\title{
20605 超高負荷直線タービン翼列内の流れに関する研究 一 入射角および翼端間隙の影響 - \\ Investigation of Flow in Ultra-Highly Loaded Linear Turbine Cascade - Effects of Incidence Angle and Tip-Clearance-
}

\author{
○学 石井 公二（法大院）橘 伸治（法大） 正 辻田 星歩（法大） \\ Koji ISHII, Hosei University, 3-7-2, Kajino-cho, Koganei-shi, Tokyo \\ Shinji TACHIBANA, Hosei University \\ Hoshio TSUJITA, HoseiUniversity
}

\begin{abstract}
An increase of turbine blade loading resulting in the downsizing and the decrease of weight of gas turbines can be achieved by the increase of blade turning angle. However, the aerodynamic performance of turbine cascade may be significantly deteriorated by the strengthened secondary flow. In this study, the oil-flow visualization and the blade surface static pressure measurements were performed for ultra-highly loaded linear turbine cascade with the turning angle of $\mathbf{1 6 0}$ degree in order to clarify the effects of the incidence angle and the tip-clearance on the secondary flow behavior. The present experimental results showed that the increase of incidence angle strengthens the horseshoe vortex and passage vortex, but not so influences the behavior of leakage vortex.
\end{abstract}

Key Words: Ultra-Highly Loaded Linear Turbine Cascade, Incidence Angle, Tip-Clearance

\section{1. 緒論}

軸流タービンの性能向上方法の一つとして, 転向角の増加 によるタービン翼の高負荷化がある. 高負荷化は翼枚数や夕 ービン段数の削減を可能とするが, 翼間圧力勾配の増大を伴 うため二次流れが増強する．その結果，損失が増加し翼列性 能が著しく低下寸る可能性がある．したがって，損失の増加 を抑え高負荷化を実現するには, タービン翼の転向角の増加 が翼列内の二次流れおよび損失生成に及ぼす影響を明らか にする必要がある。

本研究では, 転向角 $160^{\circ}$ を有する超高負荷直線タービン 翼列に対して，入射角および翼端間隙の存在が翼列内の二次 流れの挙動に及ぼす影響について, 油膜法による可視化実験 および翼面静圧測定により明らかにした。

\section{2. 供試翼形状および試験装置}

本研究で用いた供試翼形状を図 1 に, 翼列の主な仕様を表 1 に，また試験装置の概略図を図 2 に示す。供試翼はスパン 方向に翼断面形状が一様な二次元翼である. また，Tip 側に 厚さ $2 \mathrm{~mm}$ のスペーサーを着脱することで翼端閒䏚を設定し た。したがって，翼端閒隙が存在する場合のその高さは, 翼 高さ $H$ の $2 \%$ ある. 試験装置は吸い込み型風洞で, 翼列軸 方向と入口案内板がな寸角度 $\beta_{i}$ を流入角, 翼列軸方向と出口 案内板がなす角度 $\beta_{o}$ を流出角とした． $\beta_{i}$ および $\beta_{o}$ は任意の 角度に設定可能な構造となっている。

\section{3. 実験方法}

\section{1 実験条件}

本研究では入口案内板の角度 $\beta_{i}$ を変化させることにより, 表 2 に示す值に入射角を変化させて実験を行った．また，入 射角の変化に伴い翼列上流側の案内板間の流路幅が変化す るため，すべての入射角において流量が同一になるように入 口流速を設定した. 出口案内板の角度 $\beta_{o}$ は設計入射角に拀け る自然流出角 $83.5^{\circ}$ に設定した ${ }^{(1)}$. また，すべての入射角に おいて軸方向翼弦長と翼列下流における流速から算出した レイノルズ数は約 $2.5 \times 10^{5}$ である.

\section{2 油膜法による可視化実験}

固体壁面上の流跡線の可視化に用いた油膜は二酸化チ夕 ン, 流動パラフィン, オレイン酸を配合して生成した。この 油膜を図 2 に示す測定領域内の翼表面と Endwall(以下 EW) に均一に塗布し, 送風機を約 1 時間運転した後, 形成された 油膜のパターンをデジタルカメラにより記録した。

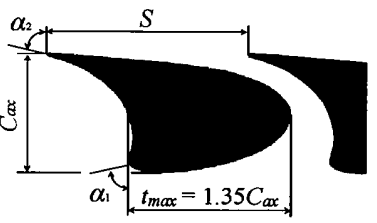

Fig.1 Test blades
Table 1 Major specifications of cascade

\begin{tabular}{|ll|c|}
\hline Number of blades & 8 \\
\hline Chord length & $C(\mathrm{~mm})$ & 80 \\
\hline Axial chord & $C_{a x}(\mathrm{~mm})$ & 68.5 \\
\hline Blade span & $H(\mathrm{~mm})$ & $100(98)$ \\
\hline Blade pitch & $S(\mathrm{~mm})$ & 114.28 \\
\hline Inet metal angle & $a_{1}(\mathrm{deg})$. & 80 \\
\hline Outlet metal angle & $a_{2}(\mathrm{deg})$. & 80 \\
\hline
\end{tabular}

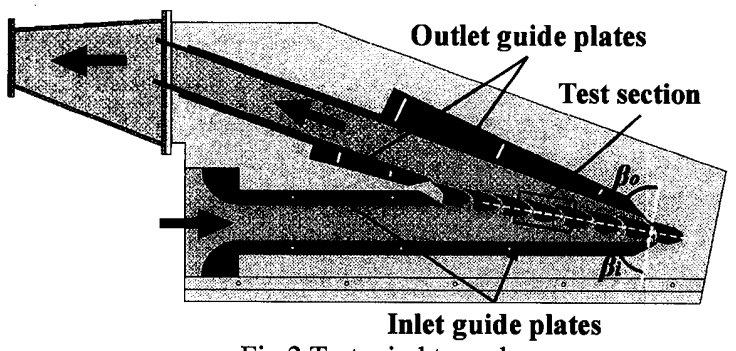

Fig.2 Test wind tunnel

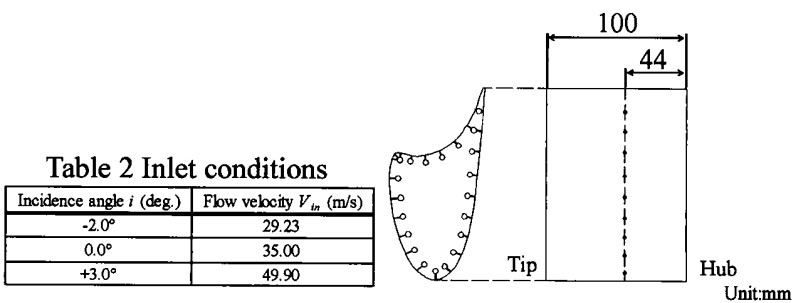

Fig.3 Static pressure taps on blade surface 


\section{3 翼面静圧測定}

翼面静圧測定用の翼を図 3 に示す．同翼には直径 $0.5 \mathrm{~mm}$ の静圧孔が翼面上に 25 点, 翼面に垂直にあけられている. 同翼を図 2 に示す測定領域内に取り付けて翼面静圧の測定を 行った. 翼面静圧の評価は次式で定義される翼面静圧係数 $C_{p s}$ で行った.

$$
C_{p s}=\frac{p_{s}}{p_{a}}
$$

ここで, $p_{s}$ は翼面静圧(ゲージ圧), $p_{a}$ は大気圧である.

\section{4. 実験結果および考察}

\section{1 入射角の影響}

翼端閒隙無しの場合の Hub 側 $\mathrm{EW}$ 上と負圧面後半部の各 入射角に対する油膜法による可視化結果を図 4 と図 5 にそれ ぞれ示す，なお図中の LE は前縁, TE は後縁, PS は圧力面, SS は負圧面を示している。.また翼端閒隙無しの場合の各入 射角に対する Midspan(以下 MS)近傍における翼面静圧係数 $C_{p s}$ の軸方向分布を図 6 に示寸. 図中の $Z / C_{a x}$ は軸方向無次元 距離であり， 0.0 が前縁， 1.0 が後縁に対応している.

$\mathrm{EW}$ 上の流跡線より $i=0.0^{\circ}$ において翼前縁付近から隣接 翼負圧面に向かう馬蹄形渦のはく離線が確認できる(図 4(b)). さらに，そのはく離線は下流へ向かうにしたがって，馬蹄形 渦の下流で発達した端壁境界層により形成される流路渦の はく離線へとつながり, 負圧面上を MS 一向かって伸びて行 くことが確認できる(図 5(b)). 入射角の増加に伴い, 翼面負 荷が増加しており(図 6), 馬蹄形渦のはく離線が負圧面に交 差する角度が増加している(図 4). さらに，馬蹄形渦および 流路渦のはく離線の MS への移動距離も増加している(図 5). これは入射角の増加に伴う翼面負荷の増加に加えて, 翼間流 路入口付近における一翼間流路あたりの流路幅の拡大率が 増加するため, 同領域における減速率が増加し, $\mathrm{EW}$ 上の境 界層が発達することで馬蹄形渦および流路渦が増強された ためであると考えられる

\section{2 翼端間隙の影響}

翼端間隙が存在する場合の翼先端面，Tip 側 EW 上，負圧 面後半部の各入射角に対する油膜法による可視化結果を図 7, 図 8 および図 9 にそれぞれ示す. また, 図 8 中の赤線は同領 域における供試翼列の輪郭線を示している。

入射角 $i$ の増加に伴い，翼端間隙内前半部では流れ角が増 加しているが, 後半部においてはほぼ同じ流れ角になってい る(図 7,8). その結果, 漏れ流れの翼端間隙への流入領域は, $i=-2.0^{\circ}$ では圧力面から負圧面前半部に渡って存在している が，i の増加に伴い圧力面側からの流入が支配的となってい ることが分かる. また，漏れ流れの流出領域は $i$ による影響 は殆ど無く負圧面後半部に位置しており，これは $i$ とは無関 係に負圧面後半部 $\left(Z / C_{a x} \fallingdotseq 0.5 \sim 0.8\right)$ に存在する低圧領域一, 間隙内の漏れ流れが向かうためと考えられる(図 6). 流入領 域の翼端面角部に沿って，はく離泡の存在を示すはく離線と 再付着線が確認できる(図 7). また, $i$ の増加に伴い Tip 側 EW 上にも圧力面側の流入領域に沿ってはく離線が現れている (図 8). この現象は $i$ の増加に伴い圧力面から流入する漏九流 れが強くなり，翼端面角部のはく離泡が拡大することを示し ていると考えられる. Tip 側 EW 上に現れている漏れ渦のは く離線の挙動に対する $i$ の影響については(図 8), 漏孔渦の開 始位置および負圧面から離脱する距離についてもあまり変 化は見られない．また，負圧面後縁部の Tip 側に漏れ渦の流 跡線が僅かに確認できるが(図 9), $i$ の影響はあまり見られな い. この原因としては，先に述べたように $i$ の増加に伴い， 間隙内への流入領域は縮小するが流入する漏れ流れが強く なり, 結果的に流出領域における漏孔流れの強さが $i$ の変化 にあまり影響を受けなかったためと考えられる。

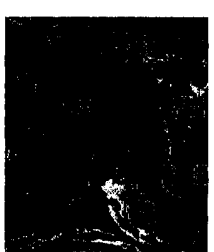

(a) $i=-2.0^{\circ}$

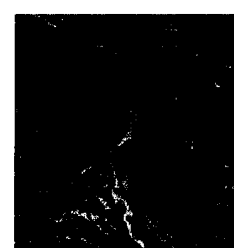

(b) $i=0.0^{\circ}$

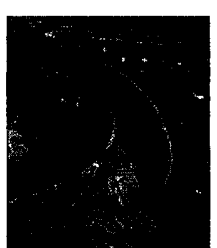

(c) $i=+3.0^{\circ}$
Fig.4 Oil-flow visualization on endwall without tip-clearance

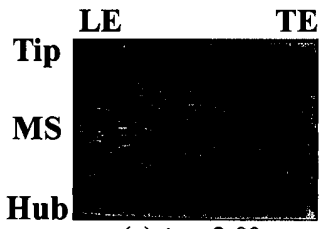

(a) $i=-2.0^{\circ}$

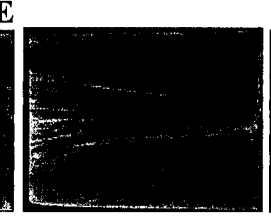

(b) $i=0.0^{\circ}$

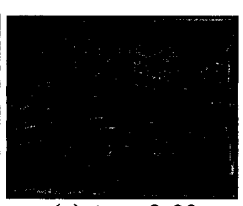

(c) $i=+3.0^{\circ}$
Fig.5 Oil-flow visualization on suction surface without tip-clearance

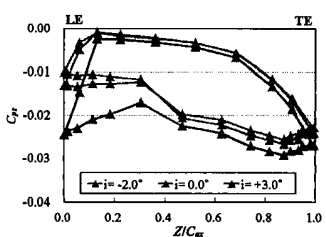

Fig.6 Blade surface static pressure without tip-clearance (MS)

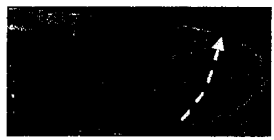

(a) $i=-2.0^{\circ}$

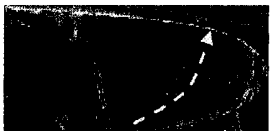

(b) $i=0.0^{\circ}$

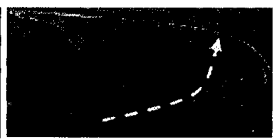

(c) $i=+3.0^{\circ}$
Fig.7 Oil-flow visualization on blade tip surface

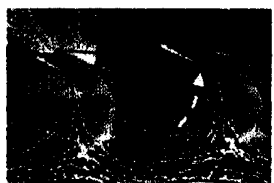

(a) $i=-2.0^{\circ}$

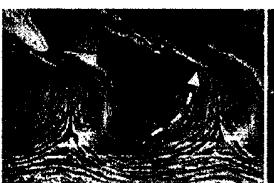

(b) $i=0.0^{\circ}$

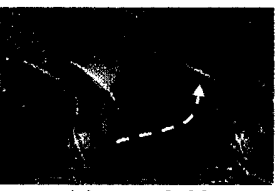

(c) $i=+3.0^{\circ}$
Fig.8 Oil-flow visualization on tip-side endwall

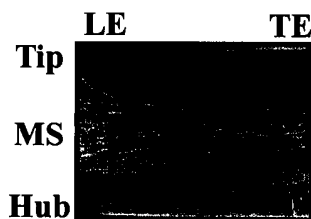

(a) $i=-2.0^{\circ}$ TE

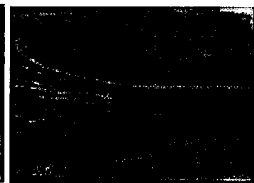

(b) $i=0.0^{\circ}$

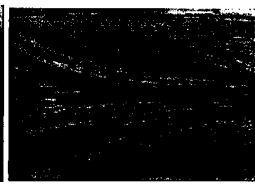

(c) $i=+3.0^{\circ}$
Fig.9 Oil-flow visualization on suction surface with tip-clearance

\section{5. 結論}

本研究により以下の結論を得た。

（1）超高負荷直線タービン翼列において，入射角の変化およ び翼端閒隙の存在が翼列内の二次流れの挙動に及ぼす影 響を実験により明らかにした。

（2）入射角の増加は負荷の増加に加えて，翼間流路入口にお ける一翼間流路あたりの流路幅の拡大率を増加させ，同 領域における $\mathrm{EW}$ 上の境界層を発達させることで馬蹄形 渦および流路渦を増強する。

（3）入射角の増加は，漏れ流れの翼端間隙内人の流入領域を 縮小するが，流入する漏れ流れを強くするため，漏孔渦 の挙動にはあまり影響を与えない.

\section{参考文献}

(1) 江藤, 朝賀, 辻田, 水木, 山本, 日本機械学会東北支部 第 40 期総会·講演会講演論文集, No.051-1,(2005-3),pp.12-13. 